\title{
PERCEPTION AND ACTION IN ONE. IMPACT OF INTERACTIVE ART WORKS ON THE OBSERVER-PARTICIPANT
}

\author{
Svetoslav Kosev, Atanas Markov \\ "St. Cyril and St. Methodius" University of Veliko Tarnovo \\ Dept. Graphic Design and Visual Communications, Bulgaria \\ kosevsa@gmail.com
}

\begin{abstract}
Summary: In the visual arts, in addition to the spiritual continuity and physical presence of the observer, another process takes place - the process of perception and action. In interactive works, the two processes overlap. The participant in the interaction alters to some extent the appearance of the object and thus, also, their own aesthetic experience. The ideological content is revealed only when the observer encounters the interactive work and through his actions becomes a participant in the creative experience.

The author's project is designed to facilitate the experience of the audience by provoking them to gain knowledge about it. The project became a 'laboratory' for creative and scientific research, through which we made some important conclusions about the perception and action of the observer-participant in the creative art installations.
\end{abstract}

Keywords: Interactive Art; Interactive Installation; Perception; Action; Phenomenology

\section{ВЪЗПРИЯТИЕ И АЕЙСТВИЕ В ЕАНО. ВЪЗАЕЙСТВИЕ НА ИНТЕРАКТИВНИ АРТ ПРОИЗВЕАЕНИЯ ВЪРХУ НАБАЮААТЕАЯ-УЧАСТНИК}

\author{
Светослав Косев, Атанас Марков \\ ВТУ "Св.Св. Кирил и Методий“, В. Търново, България \\ Катедра "Графьичен Аизайн и визуални комуникации"
}

\begin{abstract}
Резюме: Във визуалните изкуства към Ауховната приемственост на наблюдателя и фризическото присъствие се появява и друг процес - процес на възприятие и Аействие. При интерактивните произведения тези Ава процеса се припокриват. Участващият в интеракцията предизвиква Ао известна степен появата на самия обект и еАновременно с това и неговото естетическо преживяване. ИАейното сьдьржание се разкрива елва когато наблюдателят срещне интерактивната творба и чрез Аействията си става съучастник в творческото изживяване.

Авторският проект е разработен с цел $\Delta$ a се улесни изживяването на публиката, като я провокира, за да извлече
\end{abstract}




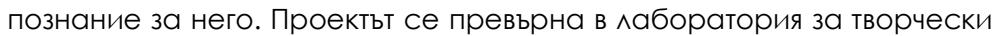
и научни изследвания, чрез които направихме някои важни заключения за възприятието и Аействието на наблюАателя-участник в интерактивните арт инсталации.

КАючови Ауми: интерактивно изкуство, интерактивна инсталация, възприятие, Аействие, феноменология

СпореА Майк Кинг третият етап („Фаза 3") в развитието на компютьрната графика, наречена „Мултимедийната ера" (King, 2002), започва с масовото разпространение на технологиите и Аостьпния интернет през 1996 г. Съзаават се нови интерактивни арт форми. Компютьрьт се използва не само за "Аигитална четка" или за визуализирането на различни математически и оризични явления, но чрез него се смесват различни елементи, които правят арт преживяването попьлно. Аобавянето на интерактивност, използването на техники от компютьрното зрение, заедно с хардуерни устройства за виртуална реалност, системи за прихващане на Авижението и още много съвременни прояви на науката и техниката, разкриват ново поле за изява на съвременния творец. В тези нови произведения, които често са интерактивни, зрителят е въвлечен във взаимодействие с творбите.

Чрез интерактивните концепции се развиват различни виАове интерорейс между човек и машина (Monika Fleischmann, Wolfgang Strauss, 1998). Във визуалните изкуства към Ауховната приемственост на наблюдателя и фризическото присьствие се появява и друг процес процес на възприятие и действие. При интерактивните произведения тези Ава процеса се припокриват. Участващият в интеракцията предизвиква Ао известна степен появата на самия обект и еАновременно с това и неговото естетическо преживяване. Илейното сьдьржание се разкрива едва когато наблюдателят срещне интерактивната творба и чрез Аействията си става съучастник в творческото изживяване. В центьра на експерименталното изследване и развитие на интерактивните инструменти стои човекът като участник и действащо мице (Monika Fleischmann, Wolfgang Strauss, 2006).

Изпробваните в меАийното изкуство интерактивни парадигми, отнасящи се $А$ тялото, Анес се изучават като нови културни техники. 
Интерактивността и Аигиталните медии стават инструменти за създаване на илентичност, които карат хората $\Delta$ а се $\Delta$ вижат.

Те предварително предугаждат бълещи комуникационни фрорми и непреднамерено подтиква Към иновации. Това най-добре се наблюдава при игровите конзоли, които са основен катализатор при развитието на интеракцията. Те показват нови начини за възприемане и същевременно разкриват съответния потенциал за комерсиално използваеми орорми (Grau, 2004).

Съзаяването на интерактивни мултимедийни произведения представлява интерАисциплинарна залача. За Създаването на този виА продукти се изискват сериозни познания в областа на софртуерното инженерство (програмиране) и хардуерни технологии, като същевременно крайният резултат е обвързан с естетическите вижАания на автора. ИзгражАането на такива проекти би трябвало Аа вкАючва екип от хуАожник, софртуерен разработчик, хардуерен инженер и др., както и самите зрители, като участници в самото произведение. ХуАожникът е с основна роля в проекта. Той отправя основното послание към публиката. Той п^анира реакциите на публиката и крайния резултат като мултимеАийно преживяване.

Следващи са софртуерните и хардуерни инженери, които могат $\Delta а$ се разглежлат като полизпьлнители. Те имат залачата $А$ реализират вижАанията на хуАОЖника, като преАложат поАхоАяща технология и Инструменти за постигане на крайния продукт в рамките на определения бюАжет. Публиката се вк^ючва в послеАния етап, когато всичко е изгралено и интегрирано в средата. Посетителите влияят на произведението с присъствието си или с Аействията си, и така стават част от преживяването.

„Силата на очакванията, а не силата на концептуалното знание, офоормя това, което виждаме в живота, не помалко, отколкото в изкуството" (Gombrich, 1961)

Как сложните операции на мозька в прелела на тялото в крайна сметка могат Аа обяснят богатата феноменология на визуалното преживяване? И има ми общи принципи, обеАиняващи възприятието и феноменологията в различните моАалности с преживяванията на Аичността?

Обикновено интуицията e, че функцията на възприятието е $\Delta а$ възстанови точно, правливо представяне на някакво външно състояние на 
нещата, например на свят, пьлен с обекти с различни форми, размери и цветове.

Тази интуиция разбира се е полвежлаща. Възприемането може да бъле „за" различни цели (Gibson, 1979) и както учените, така и художниците отАавна са признали, че възприятието и феноменологията зависят много от наблюАателя, както и от това, което се наблюАава. Уи^ям Ажеймс, бащата на съвременната психология, казва, „Аокато част от това, което възприемаме, илва чрез сетивата ни от обекта преА нас, Аруга част (може би по-голямата) винаги произлиза от нашата собствена глава" (James, 1890).

При класическите фрорми на изкуство наблюАателят само ГлеАа и това „гледане" е еАин виА действие. Той представлява „активен наблюдате^". От определен момент нататьк, когато наблюАателят се потопи в действието, неговото "пасивно гледане" се заменя с "активно наблюдение". Наблюдателят открива, че той, който не е художникьт, е този, който създава ситуацията. Когато ситуацията се промени и наблюАателят става участник, той извеАнъж започва Аа се илентифиицира със ситуацията. Наблюлението става повече от просто потребление.

В този момент консумацията спира. Това е цялата истина в интерактивните сценарии, когато наблюАателят участва в Аействието и може $а$ а се намеси в него.

Артистите и инженерите изслеАват виртуалната и фризическата интерактивност, като т^аскат технологиите и изкуството напреА по няколко фрронта, от инструменти за програмиране $\Delta о$ интерактивни инсталации, съчетаващи звук, пространство и изображение. Сьс създаването на подобни проекти и същевременно събирането и

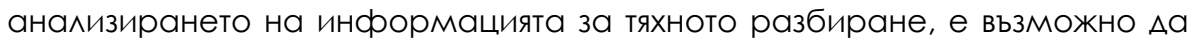
научим повече за преживяването на наблюдателя-участник и $А а$ приложим знанията за основа на бълещи проекти. За Аа стане това едрективно, е необхолимо $\Delta а$ се приложи системен по хол за придобиване на знания при събиране и анализ на необходимите Аанни.

Освен това, ако приАобитите знания ще бъдат използвани незабавно, те трябва да бьлат Аьлбоко вкоренени в реалния контекст на 
преживяването на участниците. От анализа на тази инорормация могат Аa се преАложат и отговори на изслеАователски въпроси като:

\section{Какви са изискванията за арт-технологична среАа?}

\section{Какви са възможностите за технологични иновации?}

\section{Какви са последиците за творческата практика?}

В следствие на търсения подход се появи и група Co-interaction?, чиято цел е $а$ представя подобни проекти и Аа събира и анализира

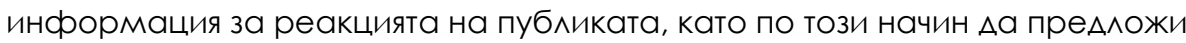
по-добро изживяване на наблюдателя-участник и по-качествена интеракция при интерактивните арт произведения. Авамата автори на статията са учредители на групата и активно „проповядват“ използването на интерактивност в произведения на изкуството, като възможност за разширяване на естетическото преживяване на публиката.

Въз основа на направени проучвания и анализи се стигна $А$ о разработването на авторския проект „Взаимолействие с технологичен организъм" (Фиг. 1.). Водещ принцип при създаването на това произведение, е изживяването на участниците, а фоокусът е съсредоточен върху разбирането и изследването на този процес, а не експлоатацията на интерактивните технологии.

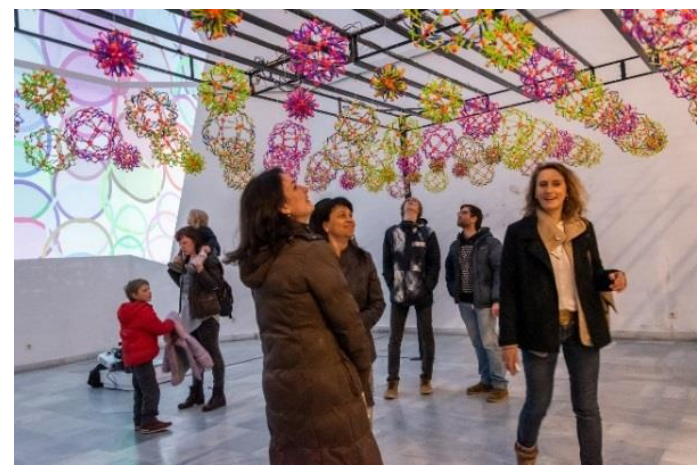

Фиг. 1. Авторски проект „Взаимодействие с технологичен организъм“ Светослав Косев, Атанас Марков, 2019 г.

Проектьт е разработен по начин, който да се улесни изживяването на публиката, провокирайки я така, че да извлече познание за него.

1 АРТ ПРОЕКТИТЕ HИ!, [www.co-interaction.com, (Last view: 12.12.2020)] 
Изживяването може $а$ а приеме различни форми, от развлечение $\Delta о$ страх, от покоряване Ао креативност, опасност, трудност, забавление. При сьздаването на това интерактивно произведение бяха следвани точно тези принципи. Така проектьт се превьрна в ^аборатория за творчески и научни изследвания, чрез които направихме някои важни заключения за възприятието и действието на наблюдателя-участник при интерактивните арт инсталации.

При тьрсената естетика на интерактивно преживяване от реакцията на публиката направихме слеАните изволи:

- Игровият елемент в произведението полтиква активното участие на наблюдателя-участник и естествено го потапя в концептуалния замисьл на автора;

- Изненадата и/или покриването на очакванията на зрителя са необхолим фактор при проектирането на интерактивни арт произведения;

- Аипсата на Аопьлнителни периферни устройства (механични ръчки, бутони, мишки, клавиатури и Ар.), които Аа зальлжават публиката $\Delta а$ извършва конкретни Аействия, улеснява взаимодействието човекпроизведение и издига изживяването на по-високо ниво;

- Използването на Аруги крайни устройства за визуализация освен мултимеАиен проектор биха направили комуникацията на публиката с произведението по-естествена;

- Средата на експониране на крайния визуален материал има огромно значение за крайното изживяване.

Тук може да подчертаем значимостта на игровия момент в интеракцията, като важен фактор, който полтиква зрителя $а$ са се превърне в участник в събитието. По този начин, приемайки „поканата“ за вк^ючване в тази своеобразна игра, той се превръща във фрактор, който има способността да влияе върху събитията. Подтикването му към Аействия в обсега на произведението му $А$ ава шанс $\Delta$ а се изолира от външния свят и $А$ а попалне в този на „играта“ и съответно в този на произведението. Във фондаменталната си книга Homo Ludens теоретикът Йохан Хьойзинха описва времевия свят, в който играта се провежАа като "магически крьг", в който важат правилата на играта, а не прави^ата на обикновения свят. Той пише: „Цялата игра се Авижи и започва в рамките 
на начертано поле, обозначено предварително материално или имагинерно... арена, карта, магически крьг, храм, сцена, екран, и т.н. всички те функционират като площалка за "Аама", т.е. изолирани места, в рамките на които важат специални правила. Всички те са времеви светове в рамките на обикновения свят, посветени на извьршването на определено Аействие." (Huizinga, 1955).

Целта на произведението „Взаимодействие С технологичен организьм“, както и на тези, които го предхожАаха, е именно такава - $\Delta а$ въведат наблюдателя в „магическия свят" на произведението, като го превърнат в част от него. Този процес би могъ^ $\Delta а$ се и^юстрира и с еАно произведение на ореноменалния нилерландски художник Морис Ешер (Maurits Cornelis Escher), което по великолепен начин илюстрира това твьрдение (ориг.2).

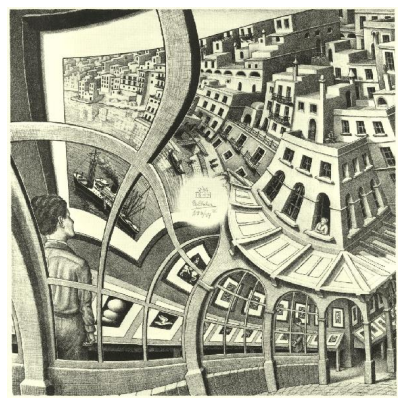

\section{Фиг. 2 - Морис Ешер „Графична галерия“ 1956 г.}

В заключение може $а$ кажем, че интерактивността се превръща в нов моде^ на възприятие и действие основно зарали експериментите на медийното изкуство. Интерактивни инструменти за игра, учене или мислене се базират на форми на комуникация и участие във вземане на решения, които полканват към колективна научна продукция. Предугаждането на културните разлики в отношението на наблюАателя приналлежи към методичните основи за проектиране и концепция на интерактивността межАу човек и машина. 


\section{АИTEPATYPA / REFERENCES}

Fleischmann, M.; Strauss, W. (1998). Images of the body in the house of illusion. [Journal] // Art@Science. - Wien/New York : Springer, 1998.

Fleischmann, M.; Strauss, W. (2006). Public Space of Knowledge - Artistic Practice in Aesthetic Computing. [Journal] // Fishwick. - Cambridge : MIT Press, 2006.

Gibson, J. J. (1979). The ecological approach to visual perception. [Book]. - Hillsdale, NJ: Lawrence Erlbaum, 1979. ISBN 978-0395270493

Gombrich, E. H. (1961). Art and illusion: A study in the psychology of pictorial representation. [Book]. - New Jersey : Princeton University Press;, 1961. ISBN 9780691070001

Grau, O. (2004). Virtual Art: From Illusion to Immersion. [Book]. - Cambridge : MIT-Press, 2004. ISBN 978-0262572231

Huizinga, J. (1955). Homo ludens; a study of the play-element of culture. [Book]. Boston: Beacon Press, 1955. ISBN 0710005784

James, W. (1890). The principles of psychology. [Book]. - New York : Henry Holt., 1890. ISBN 978-1855066793

King, M. (2002). Digital Art Museum, Creativity and Cognition in: Proceedings of the 4th Creativity and Cognition Conference. - Loughborough University : LUSAD Publications, 2002. https://doi.org/10.1145/838830.838833, (Last view: 12.12.2020) 


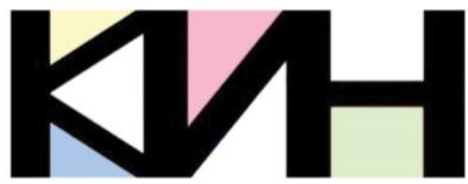

КУАТУРНО-ИСТОРИЧЕСКО НАСАЕАСТВО:

ОПАЗВАНЕ, ПРЕАСТАВЯНЕ, АИГИТААИЗАЦИЯ

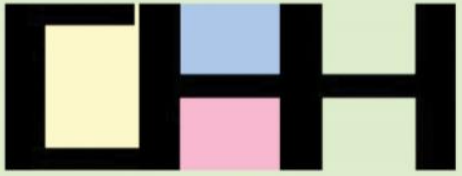

CULTURAL AND HISTORICAL HERITAGE: PRESERVATION, PRESENTATION, DIGITIZATION
Материалите в сборника са обект на авторско право. Разрешава се безвъзмезАното ползване на техни електронни/ хартиени копия само за лична употреба или обучение, при пь^но цитиране на текущата страница и слеА писмена декларация от цитиращия за мипса на търговски намерения.

(с) Авторски колектив, 2020

Техническо реАактори: Калина Сотирова-Вълкова Николай Ноев Паска^ Пиперков

\section{Editors}

Petko St. Petkov

Galina Bogdanova

This work is subject to copyright. Open and free of charge use of digital/hard copies of publications is granted only for personal or educational use, with full citation of the current page, and after written declaration of the quoting side for notcommercial Intention.

(C) Authors` Group, 2020

Technical editors:

Kalina Sotirova-Valkova

Nikolay Noev

Paskal Piperkov

НАЦИА регистрационен № 1209

Научна пореАица: том 6, брой 2 (9)/2020

Science series: vol. 6 , issue $2(9) / 2020$

NCID Registry No. 1209

www.math.bas.bg/vt/kin

ISSN: 2367-8038 